\title{
Mechanism and Kinetics of Oxidation of ZrN Ceramics
}

\author{
R. Harrison, W.E. Lee \\ Department of Materials and Centre for Nuclear Engineering, Imperial College, London, SW7 2AZ, UK
}

\begin{abstract}
Oxidation of $\mathrm{ZrN}$ ceramics from $973-1373 \mathrm{~K}$ under static conditions reveals parabolic rate behaviour, indicative of a diffusion-controlled process. In-situ high temperature XRD found the oxidation mechanism begins with destabilisation of $\mathrm{ZrN}$ through formation of a $\mathrm{ZrN}_{1-x}$ phase with oxide peaks initially detected at around $773 \mathrm{~K}$. The zirconium oxide layer was found to be monoclinic by in-situ XRD with no evidence of tetragonal or cubic polymorphs present to $1023 \mathrm{~K}$. Samples oxidised at 1173 and $1273 \mathrm{~K}$ underwent slower oxidation than those oxidised at 973 and $1073 \mathrm{~K}$. This change in oxidation rate and hence mechanism was due to formation of a denser $\mathrm{c}-\mathrm{ZrO}_{2}$ polymorph stabilised by nitrogen defects. This $\mathrm{N}$-doped dense $\mathrm{ZrO}_{2}$ layer acts as a diffusion barrier to oxygen diffusion. However, at an oxidation temperature of $1373 \mathrm{~K}$ this layer is no longer protective due to increased diffusion through it resulting in grain boundary oxidation.
\end{abstract}

Keywords: Reaction Rate, Oxynitride, Nitride, Oxidation, Zirconium

\section{Introduction}

Zirconium nitride is being considered for use in advanced nuclear power plants as inert matrix fuel (IMF) or as accident tolerant fuel particle coatings due to its high thermal conductivity (45$\left.50 \mathrm{Wm}^{-1} \mathrm{~K}^{-1}[1,2]\right)$, low neutron capture cross section and chemical compatibility with existing fuel cycle technology [3]. Due to this increased interest in $\mathrm{ZrN}$, recent work has focused on assessing thermophysical properties of $\mathrm{ZrN}$ and mixed phases of actinide nitrides dispersed in $\operatorname{ZrN}[1,2,4-10]$. However, there have been few studies on the oxidation behavior of $\mathrm{ZrN}$ which is an important factor to be considered especially under accident conditions such as occurs in a loss of coolant accident (LOCA).

The majority of oxidation studies of $\mathrm{ZrN}$ have been performed on thin films due to the extensive use of $\mathrm{ZrN}$ as a hard coating on cutting tools [11-13]. Krusin-Elbaum and Wittmer [13] studied the oxidation kinetics of $\mathrm{ZrN}$ thin films $(60 \mathrm{~nm}-1 \mu \mathrm{m})$ reporting the activation energy of oxidation to be $241 \pm 10 \mathrm{~kJ} \mathrm{~mol}^{-1}$ from $748-923 \mathrm{~K}$ with the oxide layer comprising monoclinic and cubic $\mathrm{ZrO}_{2}$. Panjan et al.[12] showed the oxidation of $\mathrm{ZrN}$ coatings with thicknesses of $300 \mu \mathrm{m}$ to have an activation energy of $229 \mathrm{~kJ} \mathrm{~mol}^{-1}$ from $773-1123 \mathrm{~K}$ and obey a parabolic rate law, in agreement with Krusin-Elbaum and Wittmer.[13] Both studies show a plateau region after initial oxidation with both authors reporting parabolic rate behavior and it was suggested the diffusion of oxygen through the oxide layer is the rate limiting step. Caillet et al. [14] studied the oxidation of $30 \mu \mathrm{m}$ ZrN coatings from 823-973 K observing linear kinetics suggesting oxygen diffusion through the oxide layer does not affect the rate, however a significant mass loss was

Email address: R.Harrison11@Imperial.ac.uk (R. Harrison) 
observed around $823 \mathrm{~K}$. The authors propose nitrogen is initially lost leaving hcp-Zr at the surface prior to $\mathrm{ZrO}_{2}$.

Zirconium oxynitrides have been produced previously by mixing of $\mathrm{ZrO}_{2}$ and $\mathrm{ZrN}$ powders [1517] or by nitriding $\mathrm{ZrO}_{2}$ under $\mathrm{NH}_{3}$ gas.[18] Three oxynitride polymorphs have been reported by Gilles et al. [17] $\mathrm{Zr}_{2} \mathrm{ON}_{2}, \mathrm{Zr}_{7} \mathrm{O}_{8} \mathrm{~N}_{4}$ and $\mathrm{Zr}_{7} \mathrm{O}_{11} \mathrm{~N}_{2}$ which are designated $\gamma, \beta$ and $\beta^{\prime}$ respectively. It can be envisaged that the formation of an oxynitride phase would be formed at the oxidation interface of $\mathrm{ZrN}$, similar to behaviour observed on oxidation of $\mathrm{Si}_{3} \mathrm{~N}_{4} \cdot[19$, 20]

$\mathrm{ZrC}$ has similar chemical properties and crystal structure to $\mathrm{ZrN}$ and its oxidation kinetics and mechanism in the bulk are better understood [21-24] with onset of oxidation occurring between 653-750 K[25] similar to that of $\mathrm{ZrN}$.[13] Oxidation of $\mathrm{ZrC}$ above $743 \mathrm{~K}$ occurs via the following sequence of steps; [21]

- Formation of a $\mathrm{ZrO}_{x} \mathrm{C}_{y}$ phase surface, which proceeds to form amorphous $\mathrm{ZrO}_{2}$ and free C.

- Crystallites of cubic zirconia $\left(\mathrm{c}-\mathrm{ZrO}_{2}\right)$ nucleate and grow to form a dense oxide layer with free carbon, which stabilises the $\mathrm{c}-\mathrm{ZrO}_{2}$.

- Oxygen then diffuses through this oxide layer to the free carbon producing $\mathrm{CO}_{2}$ which escapes via any existing cracks or pores leaving behind voids and pores in the zirconia layer which, with less carbon left to stabilise transforms to monoclinic zirconia $\left(\mathrm{m}-\mathrm{ZrO}_{2}\right)$ with small amounts of tetragonal polymorph $\left(\mathrm{t}-\mathrm{ZrO}_{2}\right)$. [25]

$\mathrm{ZrN}$ was expected to show similar oxidation properties as $\mathrm{ZrC}$ and the aims of this work were to examine the mechanism of oxidation of bulk $\mathrm{ZrN}$ samples, determining phases present in the oxidation layer and investigate the existence of different layers at the reaction interface, such as oxynitride or high temperature $\mathrm{ZrO}_{2}$ polymorphs as observed with $\mathrm{ZrC}$ ceramics.[25] Oxidation temperatures were chosen as to be able to examine the initial to intermediate stages of oxidation. The higher temperatures (1073-1373 K) are also in the range of the expected nominal operating temperature and initial temperature increases in the core following a LOCA.[26] Static atmosphere was used to aid examination of the initial and intermediate steps of oxidation and also as this is envisaged as being more akin to a LOCA whereby the coolant system fails but the nuclear reactor core remains intact.

\section{Experimental}

Commercially-available ZrN powder (Sigma Aldrich, 1-2 $\mu \mathrm{m}, \geq 99.0 \%$ ) was densified using spark plasma sintering (HP D/25/1, FCT systeme GmbH, Rauenstein, Germany) in a graphite die $(30 \mathrm{~mm}$ diameter $)$, under vacuum $(0.5 \mathrm{mbar})$. Sintering was carried out for $10 \mathrm{~min}$ at 2373 $\mathrm{K}(+100 \mathrm{~K} / \mathrm{min})$ under $50 \mathrm{MPa}$ uniaxial pressure. The resulting bulk ceramic samples had a density of $7.13 \pm 0.01 \mathrm{~g} / \mathrm{cm}^{3}$ calculated from the average of three measurements performed by the Archimedes method and a theoretical density of $97.7 \pm 0.1 \%$.

In-situ phase analysis of $\mathrm{ZrN}$ powder (Sigma Aldrich, 1-2 $\mu \mathrm{m}, \geq 99.0 \%$ ) under static air was done using high temperature (up to $1023 \mathrm{~K}$ ) X-ray diffraction (HT-XRD) (X'pert MD, Phillips, Amsterdam, Netherlands) in a furnace using a Pt heating strip (HDK 2.4, Buhler, Tubingen, Germany) at $40 \mathrm{kV}$ and $40 \mathrm{~mA}$,using Ni-filtered $\mathrm{CuK} \alpha$ radiation between room temperature and $1023 \mathrm{~K}$, with scans performed every $12 \mathrm{~K}$ between $673-1023 \mathrm{~K}$. Due to the nature of the in-situ $\mathrm{XRD}$ requiring thin layers of sample experiments were limited to powders.

Ceramic samples with dimensions $3 \times 3 \times 3 \mathrm{~mm}$ hand abraded with 600 grit SiC paper were oxidised under static air using thermogravimetric analysis coupled differential thermal analysis 
(TGA/DTA) to measure the change in weight as a function of time (STA-449-F1, Netzsch GmbH, Selb, Germany) at 5 temperatures; 973, 1073 and 1173, 1273 and $1373 \mathrm{~K}(+20 \mathrm{~K} / \mathrm{min})$ for a dwell time of $5 \mathrm{~h}$. Change in mass was continually recorded using the micro-balance of the TGA, weight change after 0, 1, 2, 3, 4, and $5 \mathrm{~h}$ time points is reported. Oxidation using the TGA ensures more reliable results in weight change as any oxide scale spallation remains in the crucible and there is no excess weight gain from the cooling of the furnace at the desired time points. Experiments were performed once at each isothermal oxidation temperature so results are directly comparable. Plots of $\triangle W / A,(\triangle W / A)^{2}$ and $(\triangle W / A)^{3}$ against time were made to determine which equation gave the the best linear fit according to equations 1, 2 and, 3 (where $\triangle W$ is the change in weight ( $\mathrm{mg}) A$ is the area of the pellet $\left(\mathrm{cm}^{2}\right), k_{l}, k_{p}$ and $k_{c}$ are the linear, parabolic and cubic rate constants respectively and $t$ is the time (s)). [20, 27, 28] Errors of $\triangle W / A$ are given as the percentage error of the TGA/DTA instrument compounded with the error from the area measurements of the pellets.

$$
\begin{aligned}
& \left(\frac{\triangle W}{A}\right)=k_{l} t \\
& \left(\frac{\triangle W}{A}\right)^{2}=k_{p} t \\
& \left(\frac{\triangle W}{A}\right)^{3}=k_{c} t
\end{aligned}
$$

Microstructural characterisation of the oxidised, polished pellets was performed using secondary electron imaging (SEI) in an SEM (JSM-6400, JEOL, Tokyo, Japan) equipped with energy dispersive spectroscopy (EDS) detector for chemical analysis (ultra thin polymer window, INCA, Oxford instruments, Oxford, UK). Focused ion beam (FEI, Helios Nanolab 600, OR, USA) was used to prepare samples and transmission electron microscope (TEM) analysis was performed on the oxidised ceramics (HRTEM FX2000, JEOL, Tokyo, Japan). Selected area diffraction (SAD) patterns were indexed by matching $d_{h k l}$ values with reference patterns and calculated SAD patterns using SingleCrystal software (version 2.2.9). Lattice parameters were calculated from the indexed SAD patterns along with the measured $d_{h k l}$ spacing's using equation 4 and contain a $2 \%$ error due to the small (0.5-50) angle of diffraction. [29]

$$
a=d \sqrt{h^{2}+k^{2}+l^{2}}
$$

\section{Results and discussion}

\subsection{Oxidation kinetics}

In-situ XRD of $\mathrm{ZrN}$ powder during oxidation is presented in figure 1. Monoclinic $\mathrm{ZrO}_{2}$ is initially detected at $773 \mathrm{~K}$ after no dwell time and was the only polymorph detected during the oxidation process which as expected since the tetragonal and cubic forms are both high temperature $(\geq 1450 \mathrm{~K})$ polymorphs. However, this is not in agreement with observations of a very low intensity reflections identified as a minor cubic $\mathrm{ZrO}_{2}$ polymorph detected by glancing angle XRD of oxidised thin films by Krusin-Elbaum and Wittmer [13]. It should be noted that the observation of low amounts of cubic $\mathrm{ZrO}_{2}$ would be difficult by in-situ XRD due to the differences in experimental technique with glancing angle diffractometers. Peak intensity is also lower in in-situ XRD compared to typical diffractometers due to the scattering from the chamber window of the furnace between the source and detector. Figure 2 shows an excerpt of the (200) $\mathrm{ZrN}$ reflection which reveals that initially the peak shifts to lower $2 \theta$ angles, corresponding to 
an increase in lattice parameter due to thermal expansion until around $673 \mathrm{~K}$. Above $673 \mathrm{~K}$ the peaks begin to shift to higher $2 \theta$ angles suggesting a decrease in lattice parameter which could arise from loss of nitrogen from the lattice resulting in a $\mathrm{ZrN}_{1-x}$. Further increase of temperature leads to the peak splitting, resulting in a peak consisting of two main components (observed for all ZrN reflections). This suggests the existence of two or more ZrN phases, such as a substoichiometric $\mathrm{ZrN}_{1-x}$ phase and $\mathrm{Zr}-\mathrm{O}-\mathrm{N}$ phase. Incorporation of oxygen into the $\mathrm{ZrN}$ lattice to form an oxynitride with the same crystal structure would result in the formation of a smaller lattice resulting in the peak shift to higher $2 \theta$. This agrees with the observations of Gendre et al.[30] who showed the lattice size of $\mathrm{ZrC}$ decreased with oxygen content to a stoichiometry of around $\mathrm{Zr} \mathrm{C}_{0.79} \mathrm{O}_{0.13}$.

The change in weight normalized for the surface area of the ceramic samples as a function of time is shown in figure 3 which reveals a non-linear relationship (equation 1) for all samples (indicated by $\mathrm{R}^{2}$ values $\leq 0.99$ for a linear fit in figure 3 ), except for the sample oxidised at 1273 $\mathrm{K}$ which fits well to a linear relationship. However, this may be because the oxidation rate is still in the linear region and longer oxidation times may show parabolic rate behaviour. Figure 4 shows the square of the weight gain normalised for surface area as a function of time for each isothermal oxidation temperature with all $\mathrm{R}^{2}$ values $\geq 0.99$ showing a good fit. All samples had a $\mathrm{R}^{2} \leq 0.97$ for a cubic relationship (equation 3 ) showing a poor fit. A parabolic rate is expected for the samples due to increased diffusion distance for oxygen through the growing oxide layer to the $\mathrm{ZrO}_{2} / \mathrm{ZrN}$ reaction interface. It can be seen from figure 3 and plotting the rate constant for each temperature (figure 5) that the samples oxidised for $5 \mathrm{~h}$ at lower temperatures (973 and $1073 \mathrm{~K}$ ) showed more weight gain than those oxidised for $5 \mathrm{~h}$ at 1173 and $1273 \mathrm{~K}$. The rate constants in figure 5 show a rapid increase between 973 and $1073 \mathrm{~K}$ followed by a large decrease at $1173 \mathrm{~K}$ and then no significant difference between samples oxidised at 1173 and $1273 \mathrm{~K}$. At the higher temperature of $1373 \mathrm{~K}$ however, the rate of oxidation is the fastest observed for all isothermal oxidation temperatures. The proposed change in mechanism between low and high temperature oxidation will be discussed further in section 3.3 .

\subsection{Oxidation layer characterisation}

The ceramic sample oxidised for $5 \mathrm{~h}$ at $973 \mathrm{~K}$ (figure 6) an outer layer of brittle, porous $\mathrm{ZrO}_{2}$ was formed which spalled away from the surface of the sample, revealed by loose powder present when removing the sample from the crucible. Figure 6a also shows light regions with increased porosity further into the bulk from the surface that EDS revealed contained oxygen and nitrogen, indicating the oxidation layer penetrated further than the surface layer. This is more clearly observed in the sample oxidised at $1073 \mathrm{~K}$ for $5 \mathrm{~h}$ (figure 7 ) where a dense but cracked layer of $\mathrm{ZrO}_{2}$ at the surface of the sample is observed on top of a cracked layer with mixed porosity which EDS also showed contained oxygen. SEIs of the samples heated to 1173 and $1273 \mathrm{~K}$ for $5 \mathrm{~h}$ are shown in figures 8 and 9 respectively. Figure 8 reveals three layers, EDS of the first two revealed only $\mathrm{Zr}$ and $\mathrm{O}$, while the third was unreacted bulk $\mathrm{ZrN}$. The presence of carbon arises from the epoxy resin used to mount the samples. The SEIs in figure 9 reveal that the grains closer to the surface (nearer to the oxide layer) are readily visible however, grains towards the bulk are not. Line scans of figure $9 b$ reveal the $\mathrm{Zr}$ counts decrease in the crack in the outer oxide layer, however, do not decrease significantly at the revealed grain boundary. This suggests the grains have been revealed by oxygen diffusion along the grain boundaries nearer to the surface. A decrease in oxide layer thickness (around $20 \mu \mathrm{m}$ thinner) between the samples oxidised at 1073 and $1173 \mathrm{~K}$ for $5 \mathrm{~h}$ was observed. The oxide scale thickness did not show a significant increase for the samples oxidised at 1173 and $1273 \mathrm{~K}$ for $5 \mathrm{~h}$. SEIs (figure 10) reveal the sample oxidised at $1373 \mathrm{~K}$ for $5 \mathrm{~h}$ showed extensive grain boundary oxidation in the bulk. 
The oxide scale is also cracked and spalled away from the sample on handling, similar to the sample oxidised at $973 \mathrm{~K}$ for $5 \mathrm{~h}$.

TEM of a FIB section of the intermediate layer observed in the sample oxidised at $1173 \mathrm{~K}$ is shown in figure 11a. The dark phase is a thick region of monoclinic $\mathrm{ZrO}_{2}$ as characterised by XRD (figure 1) and corresponds to the surface of the oxidised sample. The bulk of the sample is $\mathrm{ZrN}$ and the $\mathrm{SAD}$ pattern from this region matched $\mathrm{ZrN}$ (figure $11 \mathrm{~b}$ which indexed as the [001]ZrN zone axis). However, the calculated lattice parameter of $4.400 \pm 0.090 \AA$ is smaller than the literature value given at $4.574 \AA$.[31] The decrease in lattice size may be due to nitrogen vacancies and oxygen content causing the lattice to shrink. SAD patterns of the intermediate grain between the bulk $\mathrm{ZrN}$ grain and the surface $\mathrm{ZrO}_{2}$ are shown in figures 11c and d, which has a width of around $1 \mu \mathrm{m}$ and agrees well with the width of the layer in figure 8. The SAD pattern in figure $11 \mathrm{~d}$ indexed as the $\mathrm{c}-\mathrm{ZrO}_{2}[103]$ zone axis as the ratio of the $(\overline{3} 11) /(002) \mathrm{d}$-spacings (1.678) matches with the cubic pattern (1.658) as opposed to the ratio of 1.728 in the tetragonal $\mathrm{ZrO}_{2}[103]$ zone axis. The lattice parameters calculated from the $S A D$ patterns in figures $11 \mathrm{c}$ and $d$ were $4.877 \pm 0.100$ and $4.877 \pm 0.100 \AA$ respectively, which although $\approx 0.2 \AA$ smaller than the cubic $\mathrm{ZrO}_{2}$ lattice parameter of $5.090 \AA$ [32] match better than with the $\mathrm{ZrN}$ lattice paramter of $4.574 \AA$ [31]. Figure 12a shows a TEM image of a FIB section a grain boundary from the sample oxidised at $1373 \mathrm{~K}$ for $5 \mathrm{~h}$, which reveals the material between the $\mathrm{ZrN}$ grains in figure 10 to consist of sub-micron grains, intergranular cracking can also be seen. The SAD pattern of the sub-micron grains shown in figure 12 indexed as the cubic $\mathrm{ZrO}_{2}[1 \overline{1} 1]$ zone axis and had a lattice parameter of $4.850 \pm 0.100 \AA$. Although nitrogen has a larger atomic radii than oxygen due to its weaker effective pull on its outer electrons a decrease in observed cubic $\mathrm{ZrO}_{2}$ lattice parameter may be due to oxygen vacancies formed by substitution of oxygen with nitrogen. Evidence for ordering of oxygen vacancies and nitrogen impurities can also be observed from the forbidden reflections present in figures $11 c, d$ and figure 12 which have $d$-spacing values which are half of the fundamental refection spots, suggesting they are from superlattice reflections and not from neighbouring crystals of differing lattice size. Similar forbidden reflections and stabilisation of c- $-\mathrm{ZrO}_{2}$ by the addition of $\mathrm{ZrN}$ were observed by Van Tendeloo and Thomas [15]. The authors state that the vacancies introduced by replacing oxygen with nitrogen order along one of the three fold axes which lowers the symmetry of a rhombohedral $\mathrm{Zr}_{7} \mathrm{O}_{11} \mathrm{~N}_{2}$ phase which is closely related to the cubic fluorite structure allowing the forbidden reflections. It is plausible a similar phase may be observed in this work, however, only the observation of stabilisation of $c-\mathrm{ZrO}_{2}$ was made with certainty.

\subsection{Discussion of Oxidation Mechanism}

Parabolic rate behavior was observed for all oxidation temperatures except the sample oxidised at $1273 \mathrm{~K}$ for $5 \mathrm{~h}$, indicative of a diffusion controlled rate limiting step. The observed decrease in rate of oxidation between 1073 and $1173 \mathrm{~K}$ along with the difference in morphology of the oxidation layer cross sections (e.g. figure 7 compared to figure 8) and the presence of a high temperature c- $\mathrm{ZrO}_{2}$ phase at the oxidation layer (figures 8, 11 and 11) suggest the mechanism of oxidation changes with temperature and a schematic is shown in figure 13. At temperatures up to $1073 \mathrm{~K}$ a porous oxide layer forms, which would readily allow oxygen diffusion through pores and voids and nitrogen (or $\mathrm{NO}_{x}$ species) diffusion out of the sample. The increase in oxidation rate (figure 5) is consistent with the porous microstructure of the oxide layers (figures 6 and 7). At oxidation temperatures of $1173 \mathrm{~K}$ and $1273 \mathrm{~K}$ a dense intermediate oxide layer forms which inhibits the diffusion of oxygen and therefore the rate of oxidation. This dense layer is revealed to be $c-\mathrm{ZrO}_{2}$ by TEM results of the intermediate layer (figure 11). As the sample cools the oxide layer transforms to the monoclinic polymorph creating the cracks present in the dense $\mathrm{ZrO}_{2}$ polymorph at the surface (figures 8 and 9) due to the volume change associated 
with the polymorphic transformation. However, the sample oxidised at $1373 \mathrm{~K}$ for $5 \mathrm{~h}$ showed a rapid increase in rate of oxidation. It can be seen from the SEIs (figure 10) that there has been extensive grain boundary oxidation which would result from the increased diffusion of oxygen through the oxide scale.

Shimada and Ishil [21] describe a change in mechanism of $\mathrm{ZrC}$ oxidation with increasing temperature. At higher temperatures $(\geq 743 \mathrm{~K})$, submicron $\mathrm{c}-\mathrm{ZrO}_{2}$ crystals nucleate from the amorphous $\mathrm{ZrO}_{2}+\mathrm{C}$ layer and this forms a compact dense layer whose formation becomes the rate determining step for oxygen diffusion. However, at higher temperatures $(823 \mathrm{~K})$ and longer oxidation times the small crystallites grow and the volume expansion causes intergranular fracture providing paths for oxygen diffusion in and $\mathrm{CO}_{2}$ diffusion out. Molar volumes of $Z r N$, $m-\mathrm{ZrO}_{2}$ and $\mathrm{c}-\mathrm{ZrO}_{2}$ are presented in table 1 along with the thermal expansion data for $\mathrm{ZrN}$ and yttria-stabilised $\mathrm{ZrO}_{2}$. Thermal expansion data for ytrria stabilised $\mathrm{ZrO}_{2}$ is assumed to be similar to the stabilised $\mathrm{ZrO}_{2}$ polymoph in this work. From the values in table 1 it can be seen the associated volume change between phases and the thermal expansion mismatch between stabilised $\mathrm{ZrO}_{2}$ could both provide sources of stresses and result in intergranualr fracture. Puclin and Kaczmarek [33] examined the growth in crystal size of $\mathrm{ZrO}_{2}$ reporting a rapid increase in size of $\mathrm{t}-\mathrm{ZrO}_{2}$ at $1223 \mathrm{~K}$ and $\mathrm{m}-\mathrm{ZrO}_{2}$ at $1273 \mathrm{~K}$ which can also be envisaged as a source of stress and cracking due to the growth of submicron size of the $\mathrm{c}-\mathrm{ZrO}_{2}$ grains in the grain boundary.

From the observation of a thin $(\leq 1 \mu \mathrm{m})$ c- $\mathrm{ZrO}_{2}$ layer in the $\mathrm{ZrN}$ samples in this work (figure 8 ) and small grains $(\leq 1 \mu \mathrm{m})$ observed by TEM (figure 11) a similar rate limiting step can be envisaged for $\mathrm{ZrN}$, which causes a decreases in the rate of oxidation between the samples oxidised at 1073 and $1173 \mathrm{~K}$. However, these crystallites then grow and could transform to $\mathrm{m}$ - $\mathrm{ZrO}_{2}$ causing cracking between the grains, as observed in 12a, where it can be seen the crack follows what was the ZrN grain boundary in the oxide layer and slightly into the bulk. Berkowitz-Mattuck [34] also observed that oxidation of $\mathrm{ZrC}$ samples at temperature $\leq 1470 \mathrm{~K}$ resulted in porous $\mathrm{m}-\mathrm{ZrO}_{2}$ which fractured due to intergranular oxidation, however above $1470 \mathrm{~K}$ a denser $\mathrm{ZrO}_{2}$ layer formed slowing diffusion of oxygen to the bulk attributed to sintering effects on the oxide layer. The observations of denser outer layers of $\mathrm{ZrO}_{2}$ of the samples oxidised 1173 and $1273 \mathrm{~K}$ (figures 8 and 9) agree well with the dense $\mathrm{ZrO}_{2}$ layer reported by Shimada and Ishil [21] and Berkowitz-Mattuck. [34] Simultaneously the formation of dense scales of $\mathrm{ZrO}_{2}$ have been proposed to provide effective oxidation resistance in $\mathrm{ZrB}_{2}-\mathrm{SiC}$ [35] and $\mathrm{ZrC}-\mathrm{SiC}$ [36] composites.

Different mechanisms are thus proposed for the low temperature $(\leq 1073 \mathrm{~K})$ and higher temperature $(\geq 1173 \mathrm{~K})$ oxidation of $\mathrm{ZrN}$. The oxidation mechanism $\leq 1073 \mathrm{~K}$ can be described in several steps, initially oxygen diffusion through the surface $\mathrm{ZrN}$ grain boundaries results in a $\mathrm{ZrO}_{x} \mathrm{~N}_{y}$ phase which then forms $\mathrm{m}-\mathrm{ZrO}_{2}$. The formation of this oxide layer results in a diffusion-controlled process as observed by the parabolic kinetics shown in figure 4. Stresses from the $\mathrm{m}-\mathrm{ZrO}_{2}$ grains between the $\mathrm{ZrN}$ grains result in intergranular fracture and the creation of a porous oxide layer as observed in figure 6 , similar to the observation of Berkowitz-Mattuck for $\mathrm{ZrC}$.[34] Figure 7 also reveals lighter regions in the bulk of the $\mathrm{ZrN}$ which correspond to oxygen-rich areas formed from grain boundary diffusion of oxygen that have not yet caused fracture. The creation of these grain boundary fractures opens channels for further ingress of oxygen and removal of nitrogen advancing the rate of oxidation, this is shown schematically in figure 13 labelled $\leq 1073 \mathrm{~K}$.

Oxidation of $\mathrm{ZrN}$ at higher temperatures, however, proceeds by the formation of a high temperature $\mathrm{c}-\mathrm{ZrO}_{2}$ polymorph comprised of submicron grains. This high temperature phase is stabilised by the substitution of oxygen with nitrogen forming oxygen vacancies. As the oxidation of $\operatorname{ZrN}$ is exothermic [37], it is possible the local temperature at the interface will be higher than the oxidation temperature. This increase in temperature may give rise to sintering of the $c$ - $\mathrm{ZrO}_{2}$ crystals similar to effects observed in the oxidation of $\mathrm{ZrC}$ by Berkowitz-Mattuck [34] however, 
the nominal sintering temperature of $\mathrm{ZrO}_{2}$ is around $1673 \mathrm{~K} .[38,39]$ This dense $\mathrm{c}-\mathrm{ZrO}_{2}$ is also similar to that reported by Shimada and Ishil [21]. The dense oxide layer inhibits oxygen's ingress and therefore reduces the rate of oxidation, providing a diffusion barrier resulting in parabolic behavior and a lower oxidation as shown by the rate constants in figure 5. However, from figure 9, grains are more readily observed suggesting greater potential for oxygen diffusion via grain boundaries. Expansion of the $\mathrm{c}^{\mathrm{ZrO}} \mathrm{Z}_{2}$ crystallites or transformation to monoclinic as nitrogen defects are removed results in the cracks present in the oxide layers in figures 8 and 9. The sample oxidised at $1373 \mathrm{~K}$ for $5 \mathrm{~h}$ showed an increase in oxidation rate and this is attributed to failure of the dense oxide scale as, although oxygen diffusion through the dense zirconia layer will be slow, it will increase with temperature. This is observed as the increase in grain boundary oxidation of samples oxidised at 1273 and $1373 \mathrm{~K}$ for $5 \mathrm{~h}$ (figures 9 and 10 respectively). Thus, eventually the protective oxide scales in the samples oxidised at 1173 and $1273 \mathrm{~K}$ will fail with time as oxygen diffuses further through the dense oxide layer. Intergranular cracking observed in the TEM image of the sample oxidised at $1373 \mathrm{k}$ for $5 \mathrm{~h}$ (figure 12) will create channels for further oxygen diffusion into the sample.

\section{Conclusions}

The oxidation kinetics and mechanism of bulk ZrN ceramics between 973 and $1373 \mathrm{~K}$ have been studied. In-situ powder XRD reveals oxidation begins by removal of nitrogen from the $\mathrm{ZrN}$ lattice (forming two or more phases with smaller lattice size indicating either substoichiometric $\mathrm{ZrN}$ or a $\mathrm{ZrN}$ phase with oxygen defects) and proceeds by formation of a porous $\mathrm{m}-\mathrm{ZrO}_{2}$ phase at temperatures up to $1023 \mathrm{~K}$. Oxidation rates decreased at temperatures at or above 1173 $\mathrm{K}$ attributed to formation of a higher energy $\mathrm{c}-\mathrm{ZrO}_{2}$ phase which is proposed to slow oxygen diffusion by forming a dense layer, limiting the diffusion of oxygen to the bulk. At $1373 \mathrm{~K}$ however, this barrier to oxygen diffusion fails due to increased oxidation of grain boundaries and intergranular cracking creating more channels for oxygen diffusion. The nature of the protective scale observed for samples oxidised at 1173 and $1273 \mathrm{~K}$ for $5 \mathrm{~h}$ needs further investigation, examining longer oxidation times and oxygen pressures.

\section{Acknowledgments}

The authors are grateful to the EPSRC for financial support of this project (grant EP/J500239/1). We would also like to thank Dr D. Horlait and Dr. S. Humphry-Baker for invaluable discussions and Mr Richard Sweeney for help with the HT-XRD measurements.

\section{References}

[1] R. Harrison, O. Ridd, D. D. Jayaseelan, and W. E. Lee. Thermophysical characterisation of ceramics fabricated via carbothermic reduction-nitridation. Journal of Nuclear Materials, 454(1-3):46 - 53, 2014.

[2] M. Pukari, M. Takano, and T. Nishi. Sintering and characterization of (Pu,Zr)N. Journal of Nuclear Materials, 444(1-3):421 - 427, 2014.

[3] M. Burghartz, G. Ledergerber, H. Hein, R. R. van der Laan, and R. J. M. Konings. Some aspects of the use of $\mathrm{ZrN}$ as an inert matrix for actinide fuels. Journal of Nuclear Materials, 288(23):233-236, 2001. 
[4] A. Ciriello, V. V. Rondinella, D. Staicu, J. Somers, O. Benes, R. Jardin, D. Bouxire, F. Wastin, and E. Colineau. Thermophysical characterization of $\mathrm{ZrN}$ and $(\mathrm{Zr}, \mathrm{Pu}) \mathrm{N}$. Journal of Alloys and Compounds, 473(1-2):265-271, 2009.

[5] Y. Arai, M. Akabori, and K. Minato. Progress of nitride fuel cycle research for transmutation of minor actinides. In Advanced nuclear fuel cycles and systems (GLOBAL 2007). American Nuclear Society, 2007. (Japan) [Japan Atomic Energy Agency - JAEA, Tokai-mura, Nakagun, Ibaraki-ken, 319-1195 ].

[6] V. Basini, J. P. Ottaviani, J. C. Richaud, M. Streit, and F. Ingold. Experimental assessment of thermophysical properties of $(\mathrm{Pu}, \mathrm{Zr}) \mathrm{N}$. Journal of Nuclear Materials, 344(1-3):186-190, 2005 .

[7] Y. Arai and K. Nakajima. Preparation and characterization of PuN pellets containing ZrN and TiN. Journal of Nuclear Materials, 281(23):244-247, 2000.

[8] K. Minato, M. Akabori, M. Takano, Y. Arai, K. Nakajima, A. Itoh, and T. Ogawa. Fabrication of nitride fuels for transmutation of minor actinides. Journal of Nuclear Materials, 320(12):18-24, 2003.

[9] J. Adachi, K. Kurosaki, M. Uno, and S. Yamanaka. Effect of porosity on thermal and electrical properties of polycrystalline bulk $\mathrm{ZrN}$ prepared by spark plasma sintering. Journal of Alloys and Compounds, 432(12):7-10, 2007.

[10] H. Muta, K. Kurosaki, M. Uno, and S. Yamanaka. Thermophysical properties of several nitrides prepared by spark plasma sintering. Journal of Nuclear Materials, 389(1):186-190, 2009.

[11] Z.T. Wu, Z.B. Qi, W.F. Jiang, Z.C. Wang, and B. Liu. Influence of niobium addition on microstructure, mechanical properties and oxidation resistance of $\mathrm{ZrN}$ coatings. Thin Solid Films, 570(TACT 2013 International Thin Films Conference):256-261, 2014.

[12] P. Panjan, B. Navinsek, A. Cvelbar, A. Zalar, and I. Milosev. Oxidation of TiN, ZrN, TiZrN, $\mathrm{CrN}, \mathrm{TiCrN}$ and $\mathrm{TiN} / \mathrm{CrN}$ multilayer hard coatings reactively sputtered at low temperature. Thin Solid Films, 281-282:298 - 301, 1996.

[13] L. Krusin-Elbaum and M. Wittmer. Oxidation kinetics of ZrN thin films. Thin Solid Films, 107(1):111 - 116, 1983.

[14] M. Caillet, H.F. Ayedi, and J. Besson. Etude de la corrosion de revetements refractaires sur le zirconium i. oxydation par l'oxygene de revetements de nitrure de zirconium. Journal of the Less Common Metals, 51(2):305 - 322, 1977.

[15] G. Van Tendeloo and G. Thomas. Electron microscopy investigation of the $\mathrm{ZrO}_{2}-\mathrm{ZrN}$ system-I. Formation of an incommensurate superstructure Zr-O-N. Acta Metallurgica, 31(10):1611 - 1618, 1983.

[16] A. Ermoline, M. Schoenitz, and E. L. Dreizin. High-temperature phase equilibria in the system Zr-O-N. Journal of Materials Research, 21:320-328, 22006.

[17] J. C. Gilles. Formation d'oxynitrures a partir des oxydes refractaires. Revue internationale des Hautes Temperatures et des Refractaires, 2(3):237-262, 1965. 
[18] S. J. Clarke, C. W. Michie, and M. J. Rosseinsky. Structure of $\mathrm{Zr}_{2} \mathrm{ON}_{2}$ by neutron powder diffraction: The absence of nitride-oxide ordering. Journal of Solid State Chemistry, 146(2):399 - 405, 1999.

[19] K. L. Luthra. Some new perspectives on oxidation of silicon carbide and silicon nitride. Journal of the American Ceramic Society, 74(5):1095-1103, 1991.

[20] S. C. Singhal. Thermodynamics and kinetics of oxidation of hot-pressed silicon nitride. Journal of Materials Science, 11(3):500-509, 1976.

[21] S. Shimada and T. Ishil. Oxidation kinetics of zirconium carbide at relatively low temperatures. Journal of the American Ceramic Society, 73(10):2804-2808, 1990.

[22] K. Tamura, T. Ogawa, and K. Fukuda. The oxidation behavior of ZrC coating and powder studied by laser Raman spectroscopy and X-ray diffraction. Journal of Nuclear Materials, $175(3): 266-269,1990$.

[23] G.A. Rama Rao and V. Venugopal. Kinetics and mechanism of the oxidation of ZrC. Journal of Alloys and Compounds, 206(2):237 - 242, 1994.

[24] H. F. Jackson and W. E. Lee. Properties and Characteristics of $\operatorname{ZrC}$, book section 2.13, pages 339-372. Comprehensive Nuclear Materials. Elsevier, Oxford, 2012.

[25] Y. Katoh, G. Vasudevamurthy, T. Nozawa, and L. L. Snead. Properties of zirconium carbide for nuclear fuel applications. Journal of Nuclear Materials, 441(1-3):718 - 742, 2013.

[26] W. E. Lee, E. Giorgi, R. Harrison, A. Maitre, and O. Rapaud. Ultra-High Temperature Ceramics: Materials for Extreme Environment Applications, chapter 15 Nuclear Applications for Ultra-High Temperature Ceramics and MAX Phases, pages 391-415. John Wiley \& Sons, Inc, New Jersey, USA, 2014.

[27] X.H. Wang and Y.C. Zhou. High-temperature oxidation behavior of $\mathrm{Ti}_{2} \mathrm{AlC}$ in air. Oxidation of Metals, 59(3-4):303-320, 2003.

[28] E. Zapata-Solvas, D. D. Jayaseelan, P. M. Brown, and W. E. Lee. Effect of $\mathrm{La}_{2} \mathrm{O}_{3}$ addition on long-term oxidation kinetics of $\mathrm{ZrB}_{2}-\mathrm{SiC}$ and $\mathrm{HfB}_{2}-\mathrm{SiC}$ ultra-high temperature ceramics. Journal of the European Ceramic Society, 34(15):3535 - 3548, 2014.

[29] D. B. Williams and C. B. Carter. Transmission Electron Microscopy, volume 1. Plenum Press, New York, USA, 1996.

[30] M. Gendre, A. Maitre, and G. Trolliard. Synthesis of zirconium oxycarbide $\left(\mathrm{ZrC}_{x} \mathrm{O}_{y}\right)$ powders: Influence of stoichiometry on densification kinetics during spark plasma sintering and on mechanical properties. Journal of the European Ceramic Society, 31(13):2377 - 2385, 2011.

[31] A.N. Christensen. A neutron diffraction investigation on single crystal of titanium carbide, titanium nitride and zirconium nitride. Acta Chemica Scandinavica A, 29:563-568, 1975.

[32] P. Duwez and F. Odell. Phase relationships in the system zirconia-ceria. Journal of the American Ceramic Society, 33(9):274-283, 1950.

[33] T. Puclin and W.A. Kaczmarek. A high temperature x-ray diffraction study of the crystallisation of amorphous ball-milled zircon. Colloids and Surfaces A: Physicochemical and Engineering Aspects, 129-130(0):365 - 375, 1997. Prof. B. W. Ninham. 
[34] J. B. Berkowitz-Mattuck. High temperature oxidation: IV . Zirconium and hafnium carbides. Journal of The Electrochemical Society, 114(10):1030-1033, 1967.

[35] E. Eakins, D. D. Jayaseelan, and W. E. Lee. Toward oxidation-resistant $\mathrm{ZrB}_{2}$-SiC ultra high temperature ceramics. Metallurgical and Materials Transactions A, 42(4):878-887, 2011.

[36] B. Ma, W. Han, and E. Guo. Oxidation behavior of ZrC-based composites in static laboratory air up to $1300^{\circ} \mathrm{C}$. International Journal of Refractory Metals and Hard Materials, 46(0):159 - 167, 2014.

[37] Y. Ikuma and A. Shoji. High Temperature Oxidation of ZrN Powder in Oxygen Atmosphere. In Advanced Materials '93, pages 277 - 280. Elsevier, 1994.

[38] M. Cologna, A. L. G. Prette, and R. Raj. Flash-sintering of cubic yttria-stabilized zirconia at $750^{\circ} \mathrm{C}$ for possible use in SOFC manufacturing. Journal of the American Ceramic Society, 94(2):316-319, 2011.

[39] J. A. Downs and V. M. Sglavo. Electric field assisted sintering of cubic zirconia at $390^{\circ} \mathrm{C}$. Journal of the American Ceramic Society, 96(5):1342-1344, 2013.

[40] J. D. Hanawalt, H. W. Rinn, and L. K. Frevel. Chemical analysis by X-ray diffraction. Industrial Ėamp; Engineering Chemistry Analytical Edition, 10(9):457-512, 1938.

[41] M. Takano, M. Akabori, Y. Arai, and K. Minato. Thermal expansion of TRU nitride solid solutions as fuel materials for transmutation of minor actinides. Journal of Nuclear Materials, 389(1):89 - 92, 2009. Thermochemistry and Thermophysics of Nuclear Materials Proceedings of the Twelfth Symposium on Thermochemistry and Thermophysics of Nuclear Materials.

[42] H. Hayashi, T. Saitou, N. Maruyama, H. Inaba, K. Kawamura, and M. Mori. Thermal expansion coefficient of yttria stabilized zirconia for various yttria contents. Solid State Ionics, 176(5-6):613 - 619, 2005. 


\section{List of Figures}

1 In-situ XRD characterisation of ZrN powder from RT-1023K with scans performed every $100 \mathrm{~K}$ between RT-673 K and every $12 \mathrm{~K}$ between $673-1023 \mathrm{~K}$ with no dwell time at $1023 \mathrm{~K}$. Peaks indexed with monoclinic $\mathrm{ZrO}_{2}[40]$ and $\mathrm{ZrN}[31] \ldots .$. .

2 Excerpt of in-situ XRD of $220 \mathrm{ZrN}$ reflection from RT-1023 K, scans performed every $100 \mathrm{~K}$ between RT-673 K and every $12 \mathrm{~K}$ between $673-841 \mathrm{~K}$ with no dwell

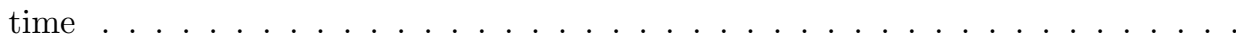

3 Change in mass per unit surface area of ceramic $\mathrm{ZrN}$ samples as a function of time for isothermal oxidation experiments . . . . . . . . . . . . . . .

4 Square of change in mass per unit surface area of ceramic $\mathrm{ZrN}$ samples as a function of time for isothermal oxidation experiments . . . . . . . . . . .

5 Parabolic rate constants $\left(k_{p}\right)$ as a function of temperature for ceramic $\mathrm{ZrN}$ samples oxidised for $5 \mathrm{~h} \ldots \ldots \ldots \ldots \ldots \ldots \ldots \ldots$

6 SEIs of oxide layer of $\mathrm{ZrN}$ sample heated to $973 \mathrm{~K}$ for $5 \mathrm{~h}$, a) shows fragmented oxide layer, b) shows grains revealed near to oxide layer . . . . . . . . . .

$7 \quad$ SEIs of oxide layer of $\mathrm{ZrN}$ sample heated to $1073 \mathrm{~K}$ for $5 \mathrm{~h}$, a) shows cracks present in bulk $\mathrm{ZrN}, \mathrm{b}$ ) shows cracks in oxide layer . . . . . . . . . . . . .

8 SEIs of oxide layer of $\mathrm{ZrN}$ sample heated to $1173 \mathrm{~K}$ for $5 \mathrm{~h}$, a) shows region where intermediate layer is penetrated by oxide scale, b) shows cracks in the oxide layer

9 SEIs of oxide layer of $\mathrm{ZrN}$ sample heated to $1273 \mathrm{~K}$ for $5 \mathrm{~h}$, a) shows distance into the bulk that grains have been revealed, b) shows cracks in oxide scale, EDS lines scans show zirconium counts (bottom left) and oxygen counts (bottom right) . .

10 SEIs of oxide layer of $\mathrm{ZrN}$ sample heated to $1373 \mathrm{~K}$ for $5 \mathrm{~h}$, a) shows oxide layer and bulk $\mathrm{ZrN}$ grains that have undergone attack by oxidation, b) higher magnification of $\mathrm{ZrN}$ grain revealed by EDS to have oxygen content between $\mathrm{ZrN}$ grains . . .

11 a) BF-TEM image of FIB section taken from intermediate layer of sample oxidised at $1173 \mathrm{~K}$ for $5 \mathrm{~h}, \mathrm{~b})$ SAD pattern of bulk region, c and d) SAD patterns of intermediate layer grains . . . . . . . . . . . . . . . .

12 a) BF-TEM image of FIB section taken from grain boundary of sample oxidised at $1373 \mathrm{~K}$ for $5 \mathrm{~h}, \mathrm{~b})$ SAD pattern of area indicated with circle . . . . . . . . .

13 Proposed mechanisms of oxidation of $\mathrm{ZrN}$ at low $(\leq 1073 \mathrm{~K})$ and higher $(\geq 1173$ K) temperatures . . . . . . . . . . . . . . . . . . . . . . 


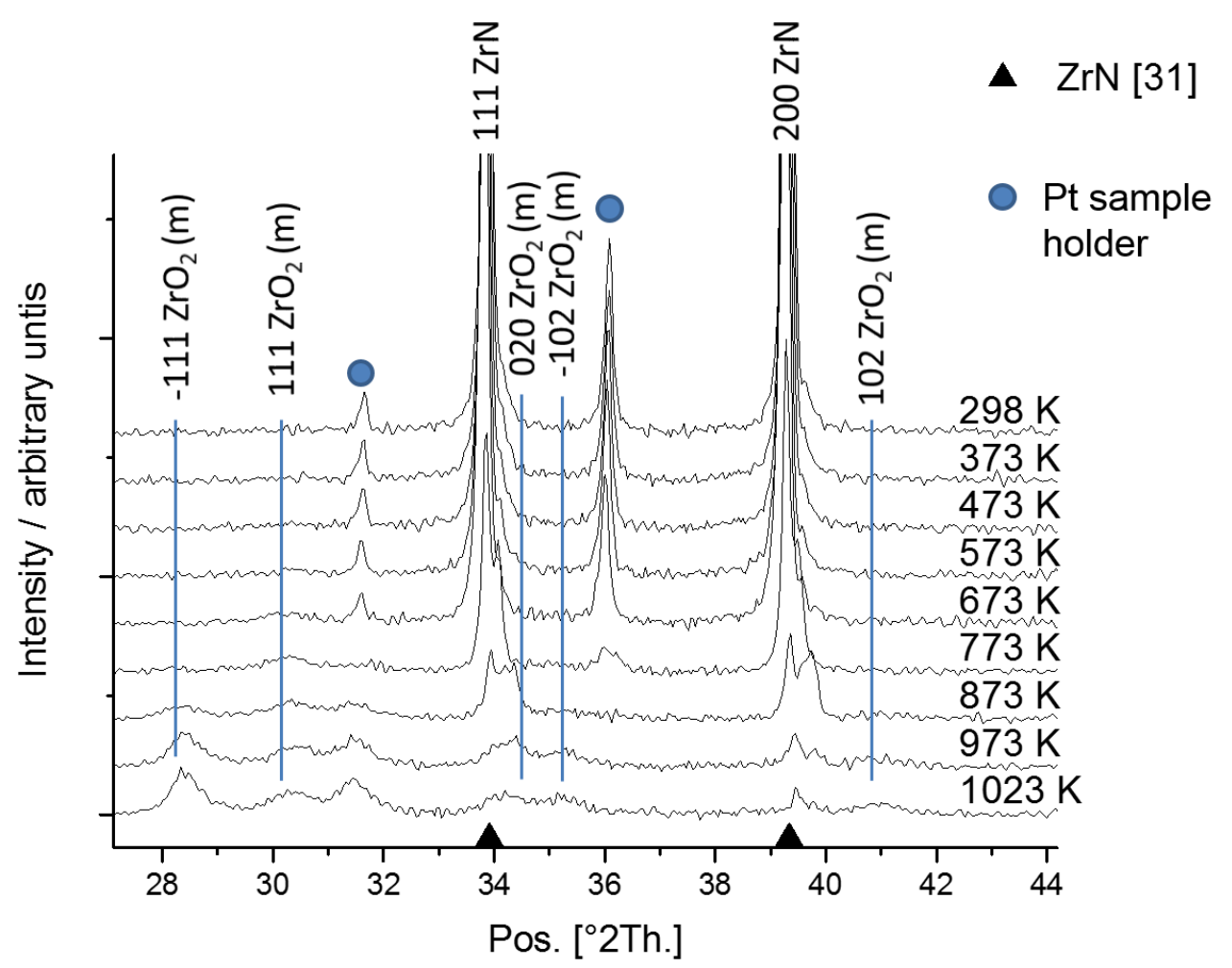

Figure 1: In-situ XRD characterisation of ZrN powder from RT-1023K with scans performed every 100 $\mathrm{K}$ between RT-673 K and every $12 \mathrm{~K}$ between $673-1023 \mathrm{~K}$ with no dwell time at $1023 \mathrm{~K}$. Peaks indexed with monoclinic $\mathrm{ZrO}_{2}[40]$ and $\mathrm{ZrN}[31]$ 


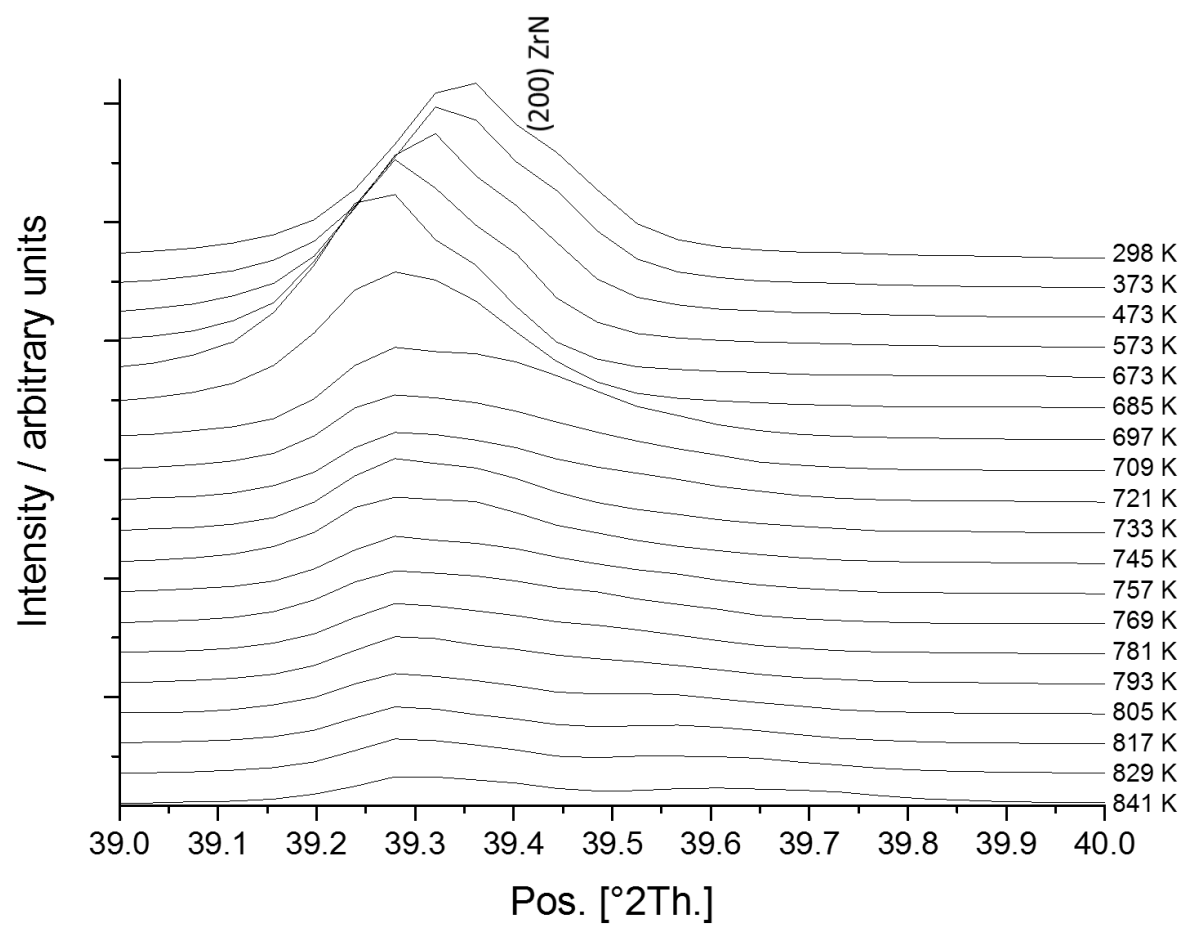

Figure 2: Excerpt of in-situ XRD of $220 \mathrm{ZrN}$ reflection from RT-1023 K, scans performed every $100 \mathrm{~K}$ between RT-673 K and every $12 \mathrm{~K}$ between $673-841 \mathrm{~K}$ with no dwell time 


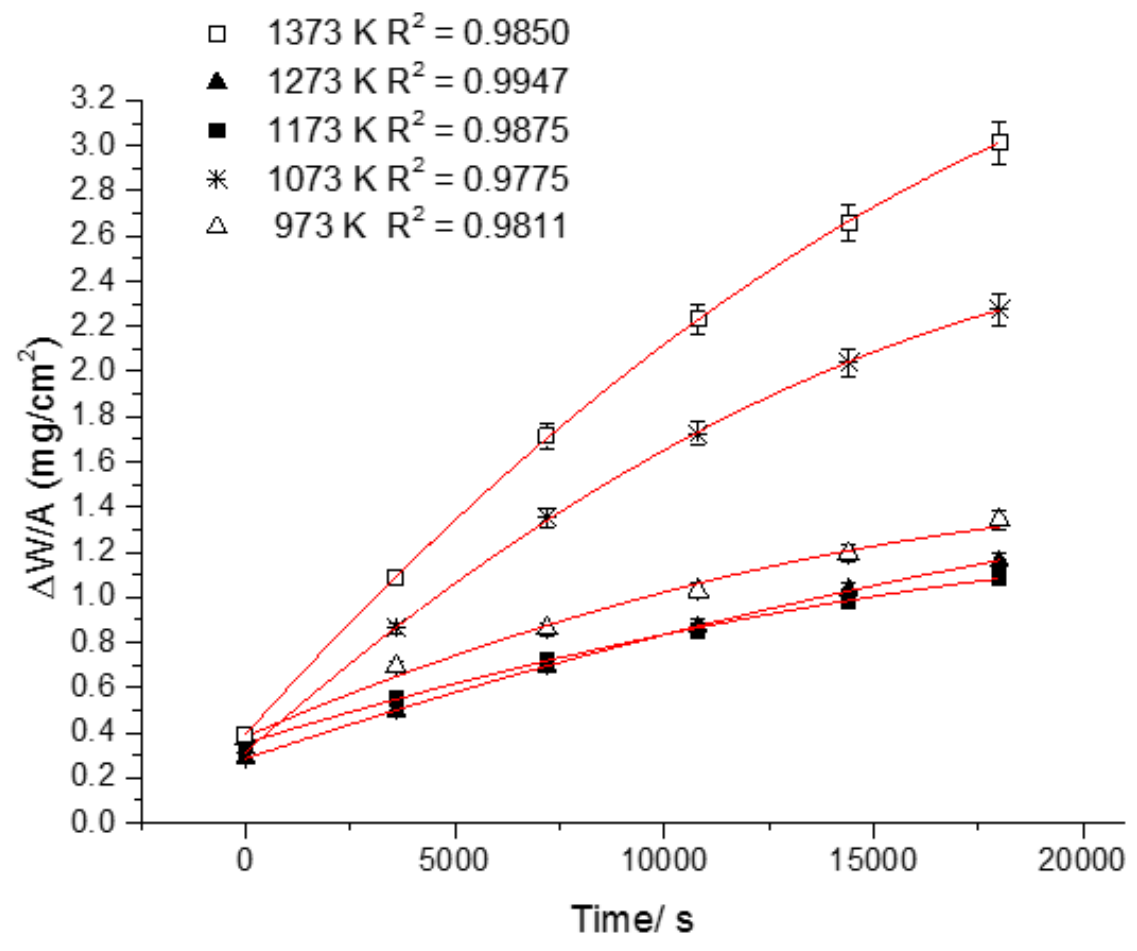

Figure 3: Change in mass per unit surface area of ceramic $\mathrm{ZrN}$ samples as a function of time for isothermal oxidation experiments 


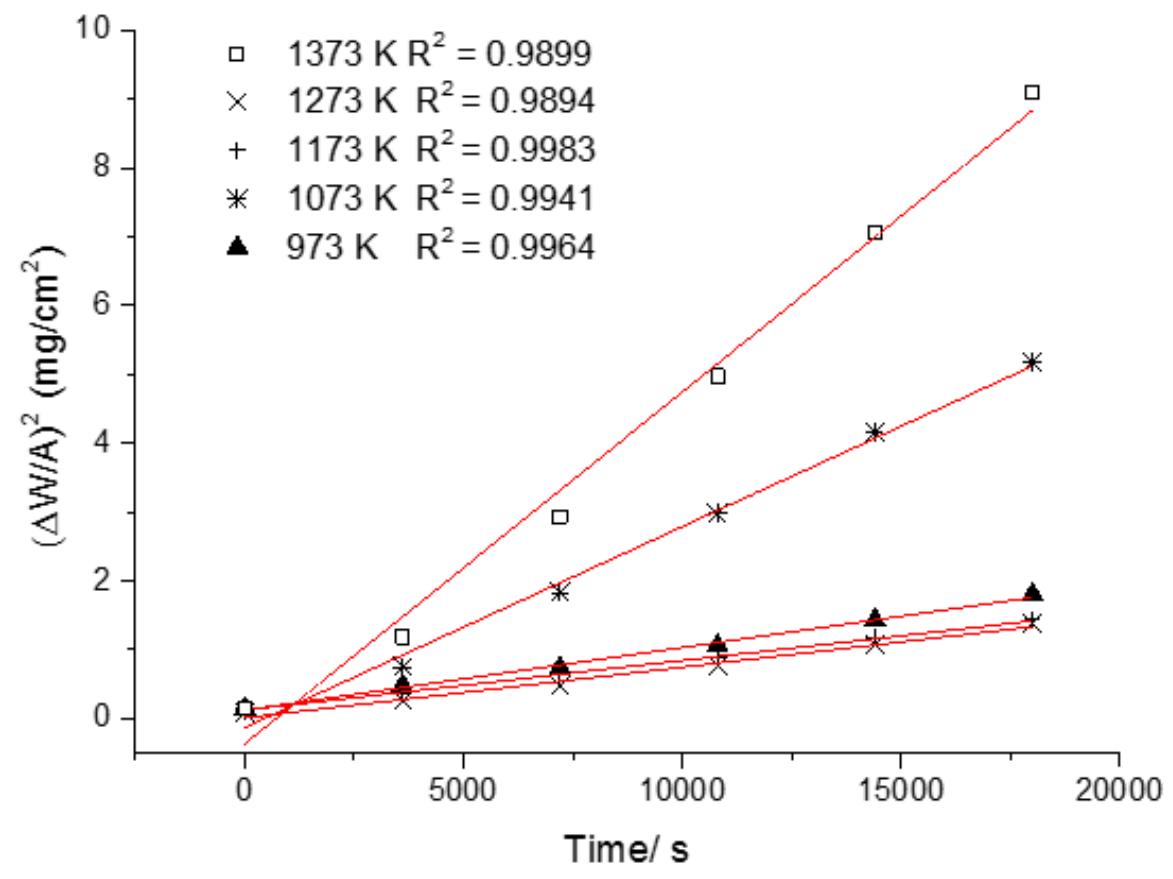

Figure 4: Square of change in mass per unit surface area of ceramic $\mathrm{ZrN}$ samples as a function of time for isothermal oxidation experiments 


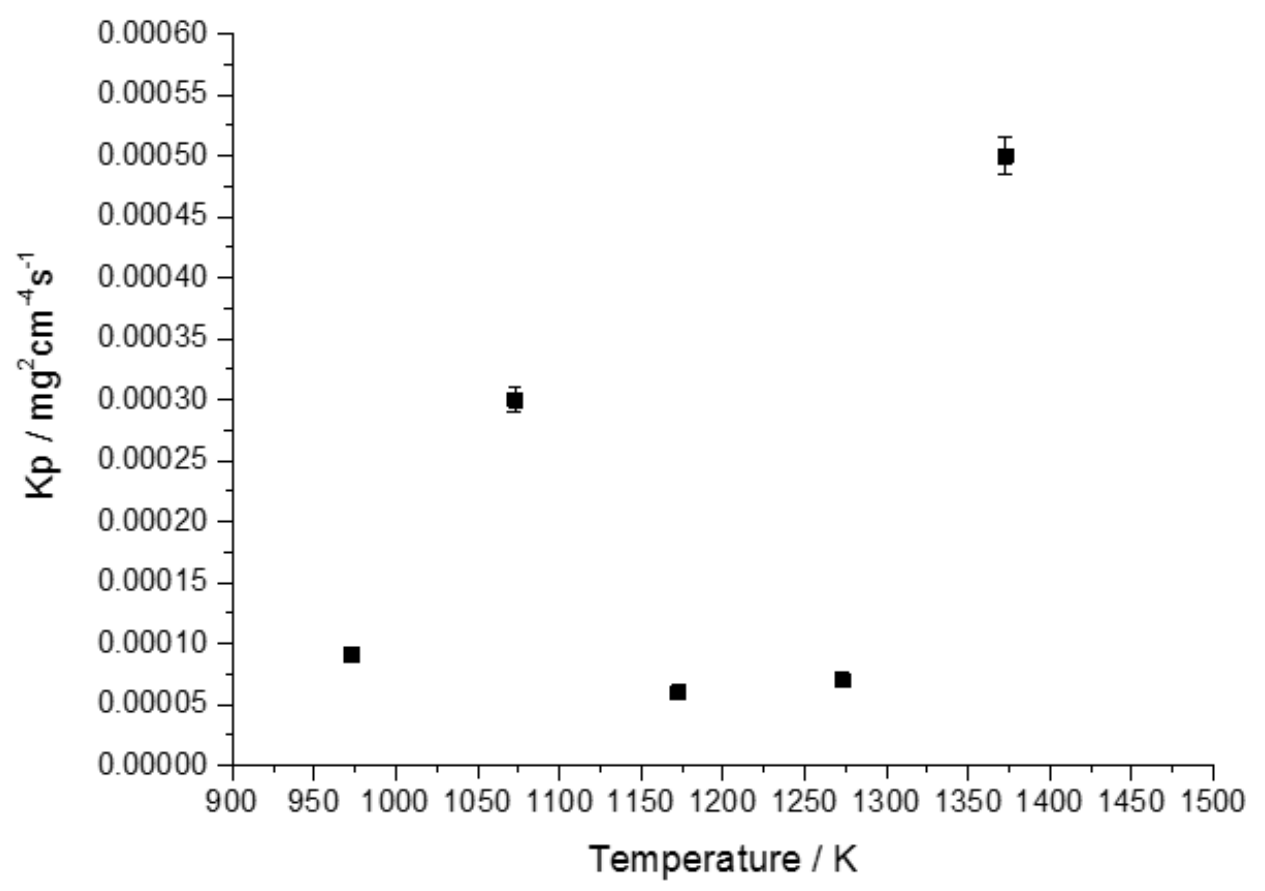

Figure 5: Parabolic rate constants $\left(k_{p}\right)$ as a function of temperature for ceramic $\mathrm{ZrN}$ samples oxidised for $5 \mathrm{~h}$ 


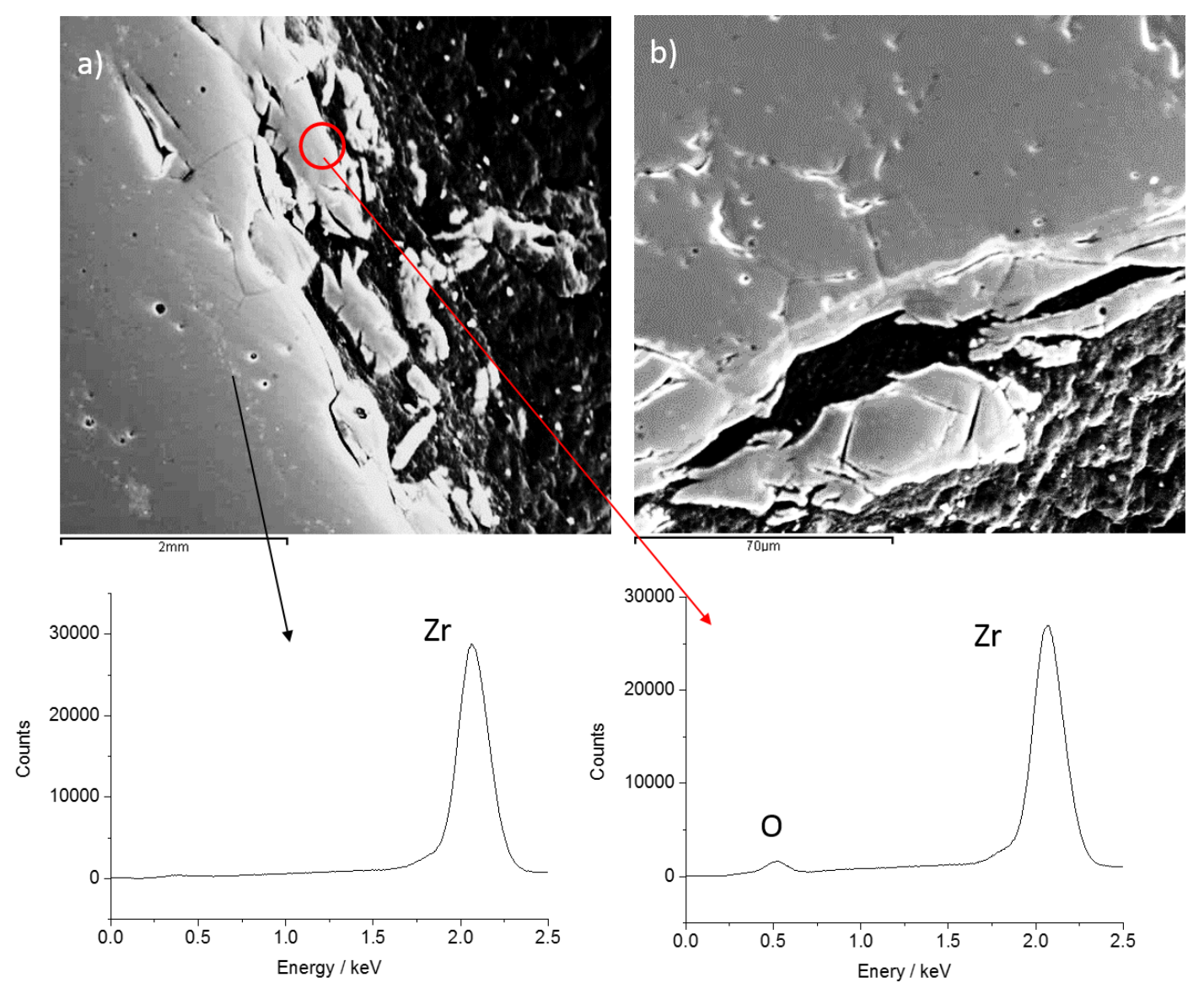

Figure 6: SEIs of oxide layer of $\mathrm{ZrN}$ sample heated to $973 \mathrm{~K}$ for $5 \mathrm{~h}$, a) shows fragmented oxide layer, b) shows grains revealed near to oxide layer 


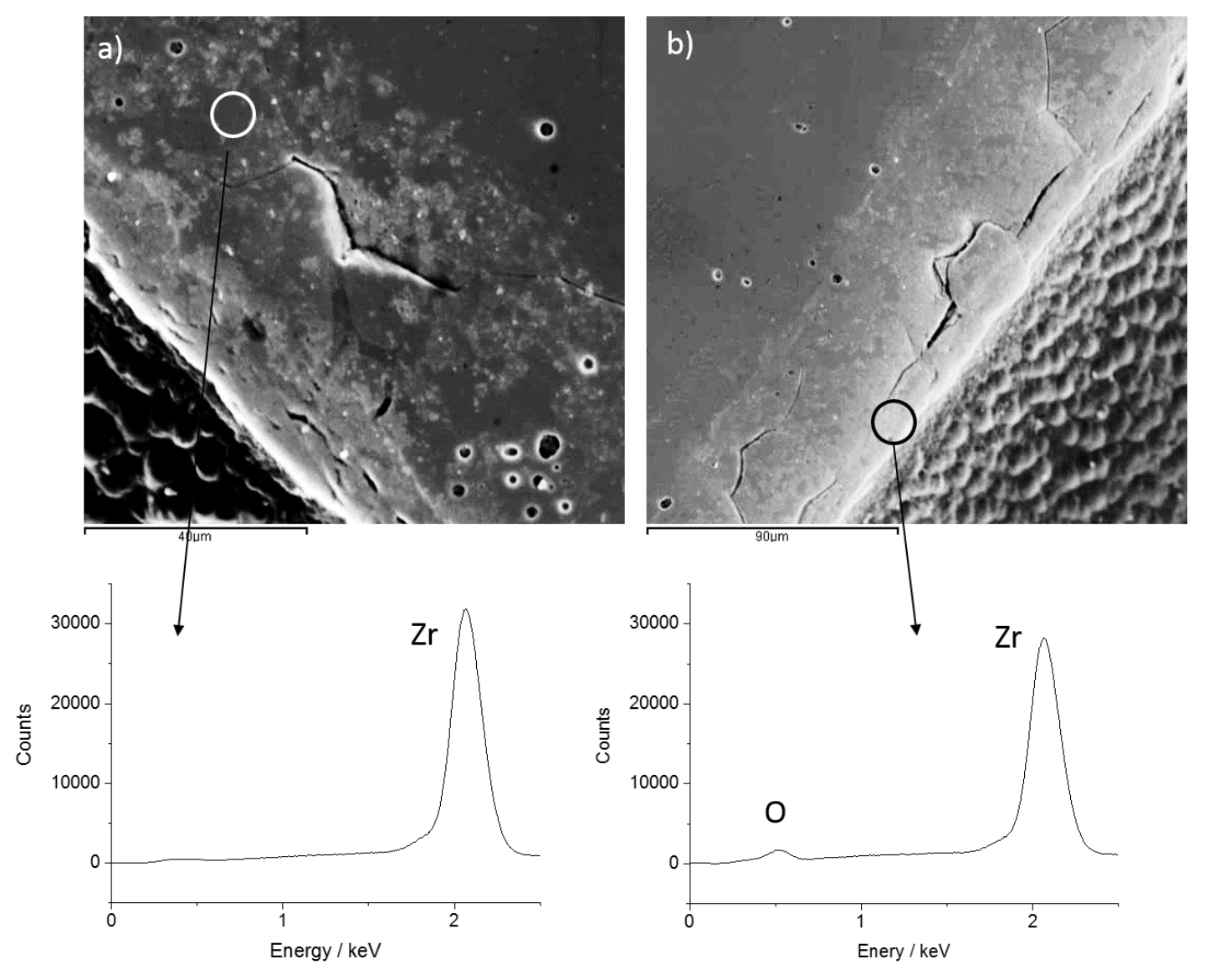

Figure 7: SEIs of oxide layer of ZrN sample heated to $1073 \mathrm{~K}$ for $5 \mathrm{~h}$, a) shows cracks present in bulk $\mathrm{ZrN}, \mathrm{b})$ shows cracks in oxide layer 


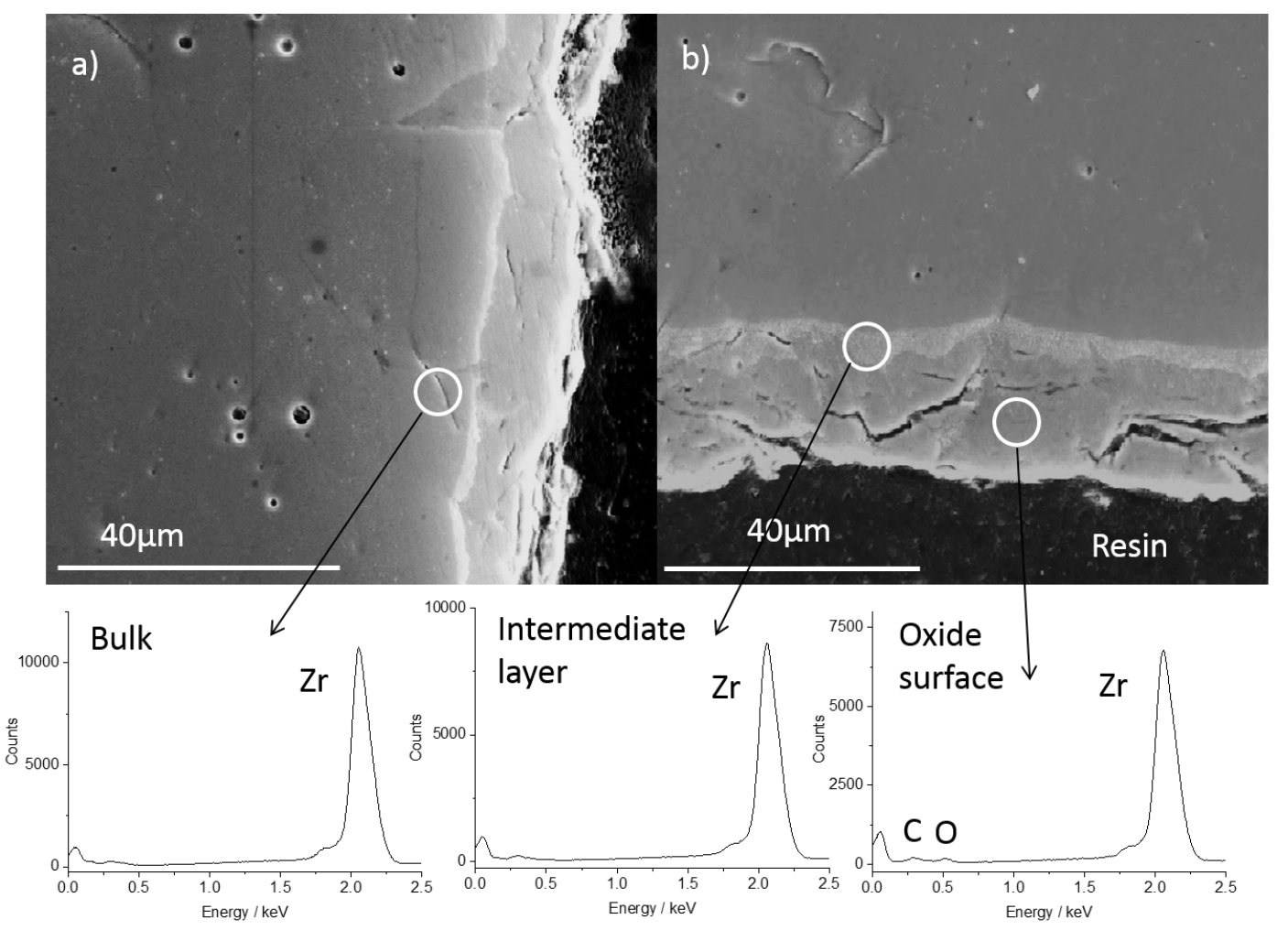

Figure 8: SEIs of oxide layer of $\mathrm{ZrN}$ sample heated to $1173 \mathrm{~K}$ for $5 \mathrm{~h}$, a) shows region where intermediate layer is penetrated by oxide scale, b) shows cracks in the oxide layer 

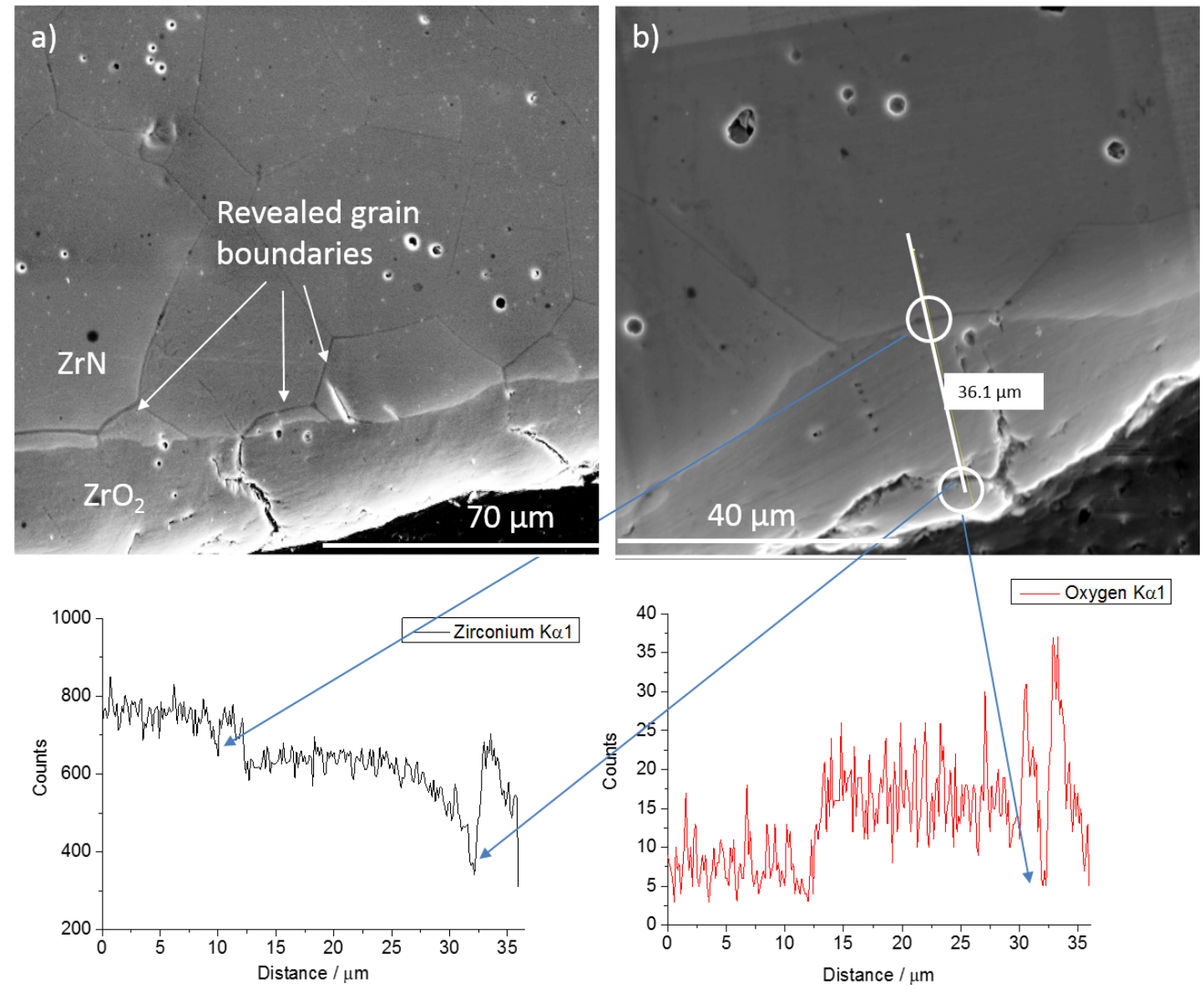

Figure 9: SEIs of oxide layer of $\mathrm{ZrN}$ sample heated to $1273 \mathrm{~K}$ for $5 \mathrm{~h}$, a) shows distance into the bulk that grains have been revealed, b) shows cracks in oxide scale, EDS lines scans show zirconium counts (bottom left) and oxygen counts (bottom right) 

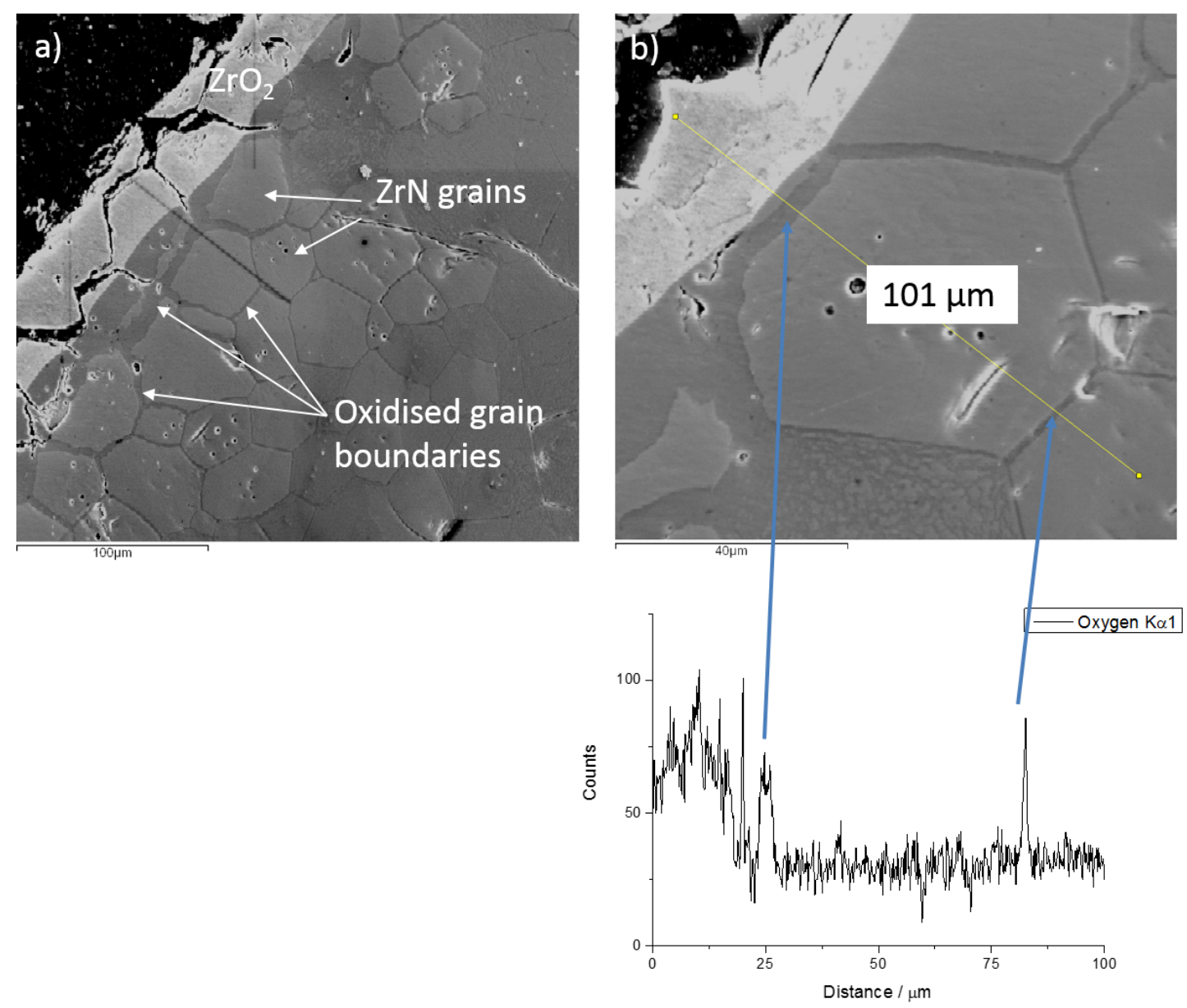

Figure 10: SEIs of oxide layer of $\mathrm{ZrN}$ sample heated to $1373 \mathrm{~K}$ for $5 \mathrm{~h}$, a) shows oxide layer and bulk $\mathrm{ZrN}$ grains that have undergone attack by oxidation, b) higher magnification of ZrN grain revealed by EDS to have oxygen content between $\mathrm{ZrN}$ grains 

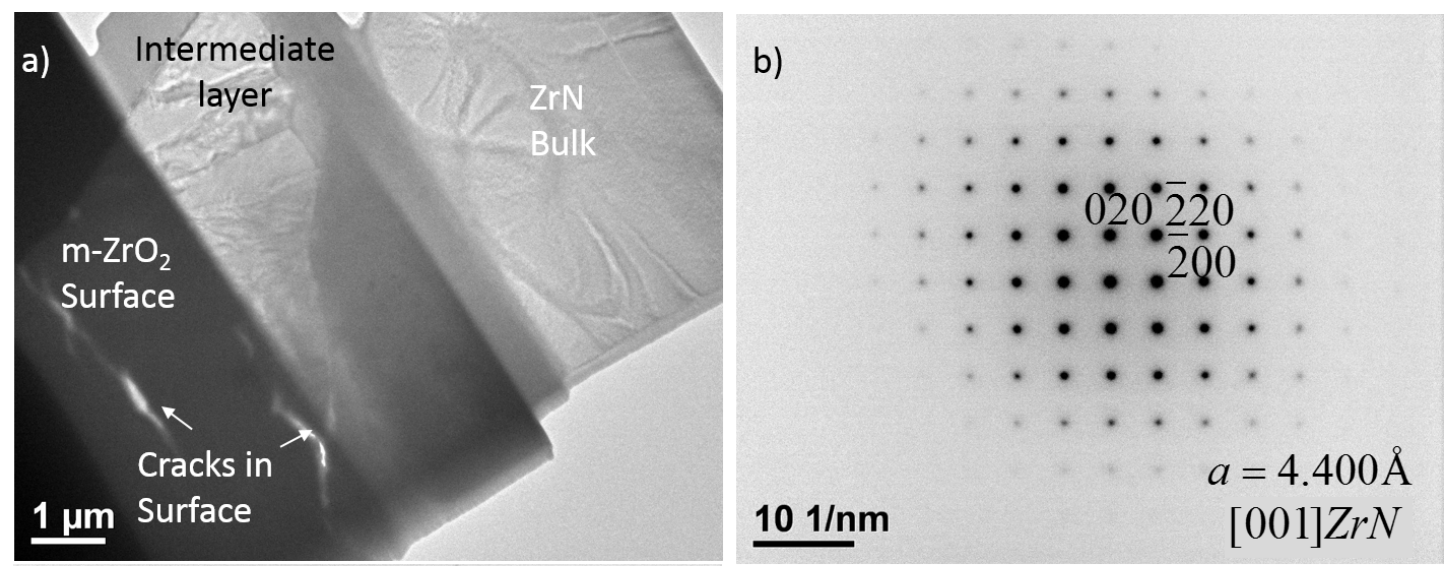

c)

d)
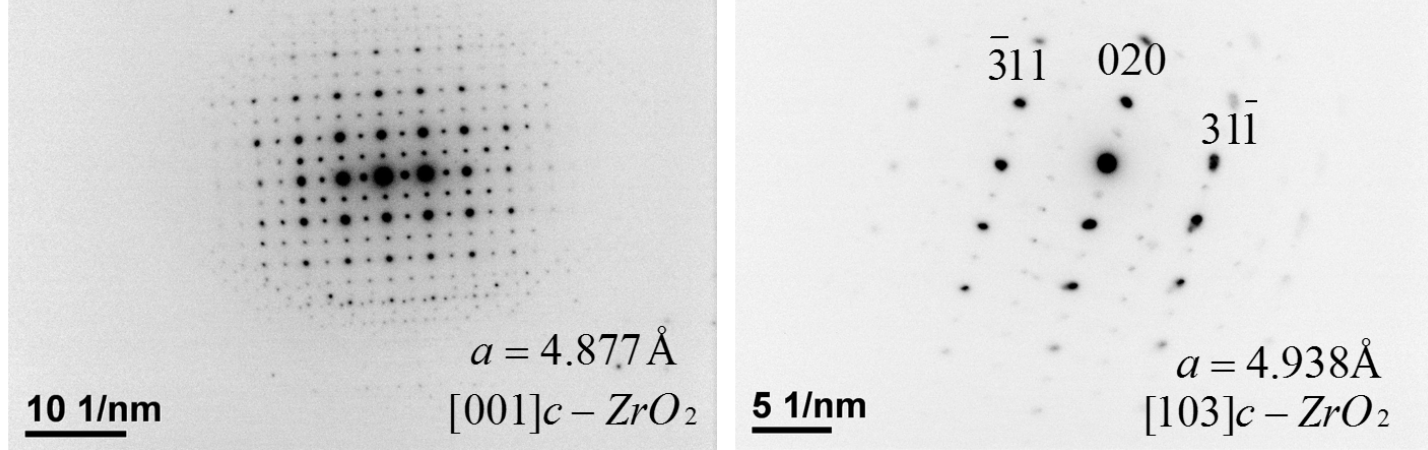

Figure 11: a) BF-TEM image of FIB section taken from intermediate layer of sample oxidised at 1173 $\mathrm{K}$ for $5 \mathrm{~h}$, b) SAD pattern of bulk region, c and d) SAD patterns of intermediate layer grains 


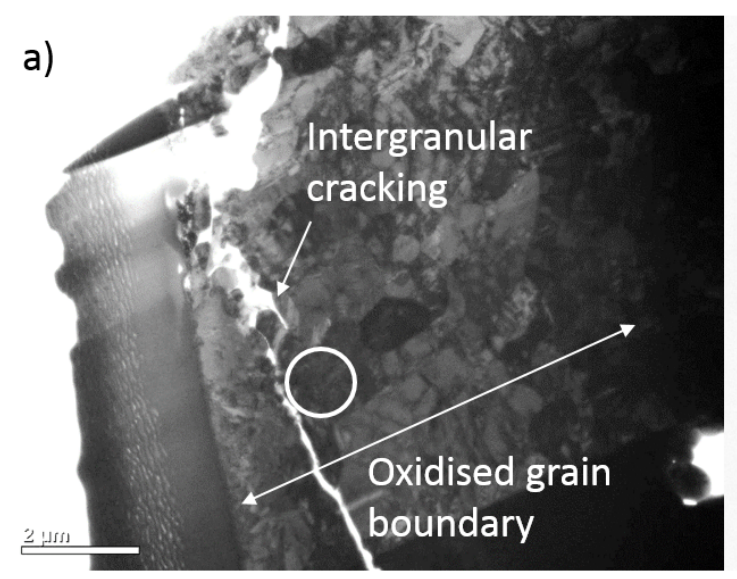

b)

Figure 12: a) BF-TEM image of FIB section taken from grain boundary of sample oxidised at $1373 \mathrm{~K}$ for $5 \mathrm{~h}, \mathrm{~b})$ SAD pattern of area indicated with circle 

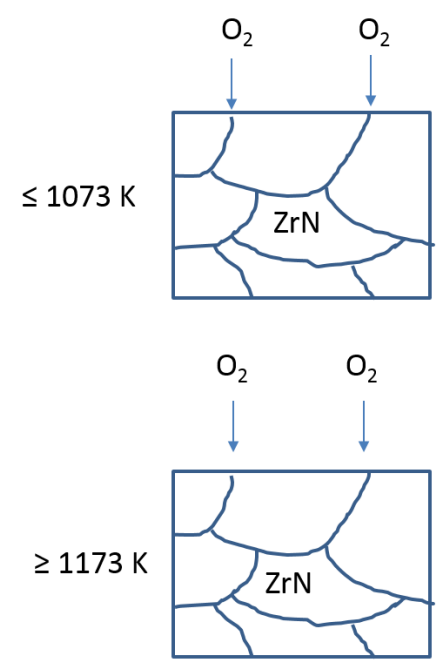

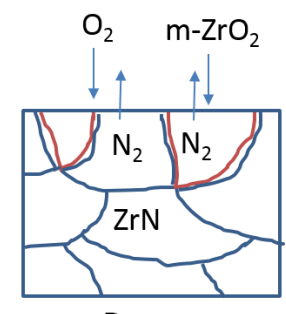

Dense

$\mathrm{O}_{2} \quad \mathrm{~N}$-stabilised $\mathrm{O}_{2}$

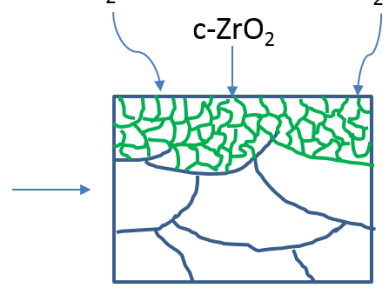

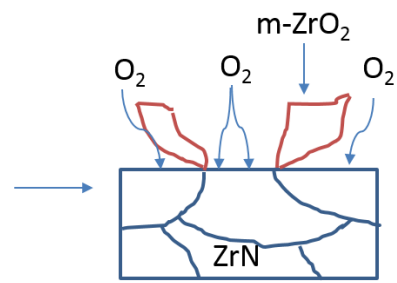

Dense/cracked

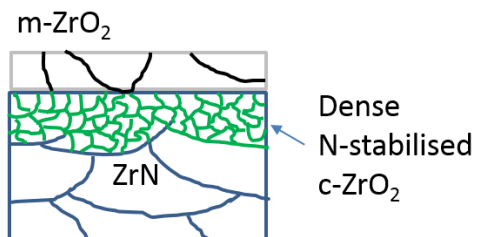

Figure 13: Proposed mechanisms of oxidation of $\mathrm{ZrN}$ at low $(\leq 1073 \mathrm{~K})$ and higher $(\geq 1173 \mathrm{~K})$ temperatures 


\section{List of Tables}

1 Molar volumes and thermal expansion coefficients of $\mathrm{ZrN}, 3 \mathrm{~mol} \%$ yttria-stabilised $\mathrm{ZrO}_{2}$, and $\mathrm{m}-\mathrm{ZrO}_{2}[40-42] \ldots \ldots \ldots \ldots$ 


\begin{tabular}{|c|c|c|}
\hline Phase & Molar volume $\left(\mathrm{V}_{m}\right)\left(\mathrm{cm}^{3} \mathrm{~mol}^{-1}\right)$ & Coefficient of thermal expansion at $1273 \mathrm{~K}\left(10^{-6} \mathrm{~K}^{-1}\right)$ \\
\hline \hline $\mathrm{ZrN}$ & 14.4 & 7.6 \\
\hline $\mathrm{c}-\mathrm{ZrO}_{2}$ & 19.6 & - \\
\hline $\mathrm{m}-\mathrm{ZrO}_{2}$ & 21.0 & - \\
\hline $3 \mathrm{~mol} \% \mathrm{Y}_{2} \mathrm{O}_{3}-\mathrm{ZrO}_{2}$ & - & 10.8 \\
\hline
\end{tabular}

Table 1: Molar volumes and thermal expansion coefficients of $\mathrm{ZrN}, 3$ mol\% yttria-stabilised $\mathrm{ZrO}_{2}$, and $\mathrm{m}-\mathrm{ZrO}_{2}$ [40-42] 